\title{
PENGARUH FRAILTY DALAM PEMODELAN MORTALITA
}

\author{
Siti Alfiatur Rohmaniah ${ }^{1}$, Novita Eka Chandra ${ }^{2}$ \\ ${ }^{1,2}$ Universitas Islam Darul Ulum Lamongan
}

\begin{abstract}
Factors that affect a person's risk of death are divided into two, namely underwriting factor and frailty factor. Underwriting factor is an observed factor, including age, occupation, history of heart disease, stroke, hypertension, diabetes, obesity, and etc. In contrast, frailty is a factor that cannot be observed, including a person's vulnerability of death. This study aims to determine the effect of frailty on mortality modeling. The modeling used is in the form of mortality model with underwriting factor using Generalized Linear Models method, and mortality model with underwriting factor using generalized linear models, and frailty factor using Generalized Linear Mixed Models method. The data in this research are longitudinal data related to underwriting factor that have binomial distribution which is taken from Health and retirement study and processed using R software. After comparing the two models, it can be concluded that frailty has an effect on mortality modeling.
\end{abstract}

Keywords: underwriting, frailty, Generalized Linear Mixed Models.

\section{PENDAHULUAN}

Perusahaan asuransi biasanya menawarkan harga premi yang besarnya dihitung hanya berdasarkan usia dan jenis kelamin. Padahal faktor yang mempengaruhi risiko kematian seseorang sangat banyak, diantaranya adalah risiko pekerjaan, riwayat kesehatan, dan lain-lain. Faktor-faktor tersebut merupakan faktor yang dapat diamati dan disebut faktor underwriting.(Brown \& McDaid, 2003).

Dari faktor underwriting ini, setiap individu pasti mempunyai kerentanan yang berbeda-beda dalam mengalami risiko kematian. Kerentanan tersebut tidak teramati karena bawaan setiap individu yang dinamakan frailty. Konsep frailtydikenalkan sebagai faktor risiko yang tidak teramati meliputi kerentanan seseorang dalam mengalami risiko kematian. Asumsi utamanya adalah terdapat suatu nilai unik yang dimiliki setiap individu, dimana nilai tersebut tetap seumur hidup individu tersebut.(Vaupel, Manton, \& Stallard, 1979).

Penelitian ini bertujuan untuk mengetahui pengaruh frailty dalam pemodelan mortalita. Sehingga dapat dimanfaatkan perusahaan asuransi dalam menentukan besarnya premi asuransi jiwa. Dengan metode ini, perusahaan dapat mengurangi risiko kerugian yang diakibatkan faktor adverse selection yaitu fenomena perusahaan asuransi tidak mampu mengcover pembayaran klaim dikarenakan harga premi asuransi yang terlalu rendah.

\section{METODE PENELITIAN}

Metode yang digunakan untuk pemodelan mortalita dengan faktor underwriting adalah metode Generalized Linear(Rohmaniah \& Danardono, 2017), sedangkan 
pemodelan mortalita dengan faktor underwriting dan frailty menggunakan metode Generalized Linear Mixed Models.

\section{A. Generalized Linear Modelas (GLM)}

Generalized Linear Models (GLM) adalah model yang digunakan untuk mengukur hubungan antara variabel respon dengan satu atau lebih variabel penjelas. Terdapat tiga komponen utama yang membentuk GLM, yaitu asumsi distribusi, komponen sistematik, dan fungsi penghubung (link function). Komponen sistematik dalam GLM berbentuk prediktor linear. Misalkan $Y_{1}, \ldots ., Y_{m}$ adalah variabel random independen, suatu fungsi penghubung disebut fungsi penghubung kanonik apabila $g\left(\mu_{i}\right)=\theta$ dengan $\theta$ adalah parameter kanonik dalam

$$
f\left(y_{i}\right)=\exp \left(\frac{y_{i} \theta_{i}-\psi\left(\theta_{i}\right)}{\phi}+c\left(y_{i}, \phi\right)\right)
$$

dengan $\psi($.$) dan c($.$) merupakan fungsi yang diketahui, \phi$ adalah parameter skala, dan $f(y)$ merupakan fungsi probabilitas variabel random $Y$ yang termasuk dalam keluarga eksponensial.Rata-rata $Y$ adalah $\mu_{i}=\psi^{\prime}\left(\theta_{i}\right)$ sedangkan variansi dari $Y$ adalah $\operatorname{Var}[Y]=\phi \psi^{\prime \prime}\left(\theta_{i}\right)=\phi V\left(\mu_{i}\right)$. (McCullagh \& Nelder, 1989)

Fungsi likelihood untuk mengestimasi parameter $\beta$ adalah:

$$
L(\beta) \propto \prod_{i=1}^{m} f\left(y_{i}\right)
$$

$$
=\prod_{i=1}^{m} \exp \left(\frac{y_{i} \theta_{i}-\psi\left(\theta_{i}\right)}{\phi}+c\left(y_{i}, \phi\right)\right)
$$

Kemudian fungsi log likelihood-nya adalah:

$$
l(\beta)=\sum_{i=1}^{m} \frac{y_{i} \theta_{i}-\psi\left(\theta_{i}\right)}{\phi}+\sum_{i=1}^{m} c\left(y_{i}, \phi\right)
$$

Turunan pertama fungsi likelihoodl $(\beta)$ adalah:

$$
\frac{\partial l(\beta)}{\partial \beta}=\frac{1}{\phi} \sum_{i=1}^{m}\left(y_{i}-\mu_{i}\right) w_{i} g_{\mu}\left(\mu_{i}\right) X_{i}^{T}
$$

dengan $w_{i}=\left(V\left(\mu_{i}\right) g_{\mu}^{2}\left(\mu_{i}\right)\right)^{-1}$.

Persamaan (4) dapat dinotasikan menggunakan matriks, yaitu: 


$$
\frac{\partial l(\beta)}{\partial \beta}=\frac{1}{\phi} X^{T} W \Delta(Y-\mu)
$$

dengan $W=\operatorname{Diag}\left[w_{i}\right]$ dan $\Delta=\operatorname{Diag}\left[g_{\mu}\left(\mu_{i}\right)\right]$.

Estimasi maksimum likelihood dari $\beta$ diperoleh dengan menentukan pembuat nol dari derivatif parsial (5) terhadap $\beta$, yaitu:

$$
\frac{1}{\phi} X^{T} W \Delta(Y-\mu)=0
$$

Persamaan (6) merupakan fungsi non linear sehingga tidak dapat diselesaikan secara analitik. Untuk menyelesaikan persamaan tersebut dapat digunakan suatu metode numerik misalnya Newton-Raphson. Turunan kedua fungsi $\log \operatorname{likelihood} l(\beta)$ adalah:

$$
\frac{\partial^{2} l(\beta)}{\partial \beta \partial \beta^{T}}=-\frac{1}{\phi} X^{T} W \Delta \frac{\partial \mu}{\partial \beta^{T}}+\frac{1}{\phi} X^{T} \frac{\partial W \Delta}{\partial \beta^{T}}(Y-\mu)
$$

Scoring Algorithmdengan iterasi ke- $m+1$ yaitu $\hat{\beta}^{(m+1)}$, secara iteratif menggunakan formula sebagai berikut:

$$
\hat{\beta}^{(m+1)}=\hat{\beta}^{(m)}+\left(X^{T} W X\right)^{-1} X^{T} W \Delta(Y-\mu)
$$

Jika $\hat{\beta}^{(m+1)} \approx \hat{\beta}^{(m)}$ (misalkan $\left\|\hat{\beta}^{(m+1)}-\hat{\beta}^{(m)}\right\|<\varepsilon$, dengan $\varepsilon$ adalah suatu bilangan positif yang sangat kecil sekali mendekati nol) maka proses iterasi berhenti dan kemudian diambil $\hat{\beta}^{(m+1)}$ sebagai estimasi dari $\beta$. Model mortalita tahunan untuk GLM adalah:

$$
q_{i t}=\frac{\exp \left(X_{i t} \beta\right)}{\left(1+\exp \left(X_{i t} \beta\right)\right)}
$$

Sedangkan untuk model dua tahunan (Rohmaniah \& Danardono, 2017) adalah:

$$
{ }_{2} q_{i t}=\frac{\exp \left(X_{i t} \hat{\beta}\right)}{\left(1+\exp \left(X_{i t} \hat{\beta}\right)\right)}
$$

B. Generalized Linear Mixed Models (GLMM)

Generalized linear mixed models (GLMM) merupakan perluasan dari GLM. Bentuk umum GLMM adalah:

$$
Y_{i j}=X_{i j} \beta+Z_{i j} b_{i}+\varepsilon_{i j}
$$


dengan $Y_{i j}$ adalah $\left(n_{i j} x 1\right)$ vektor kolom dari variabel respon, $X_{i j}$ adalah matriks $\left(n_{i j}\right.$

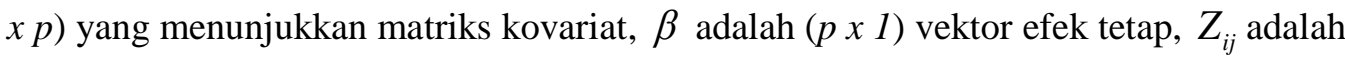
matriks $\left(n_{i j} \times q\right)$ yang menunjukkan matriks kovariat untuk efek random, $b_{i}$ adalah ( $q$ $x$ 1) vektor efek random untuk individu $i$ yang diasumsikan berdistribusi Normal dengan mean nol dan $\operatorname{Var}\left(b_{i}\right)=\sigma_{b}^{2}, \varepsilon_{i j}$ adalah $\left(n_{i j} x \quad 1\right)$ vektor kolom dari error.GLMM mengasumsikan bahwa efek random $b_{i}(i=1,2, \ldots ., m)$ saling independen dan berdistribusi identik.(Gałecki \& Burzykowski, 2013)

Untuk mengestimasi parameter $\beta$ dalam GLMM menggunakan maksimum likelihood diasumsikan bahwa $Y_{i j}$ mengikuti distribusi dari keluarga eksponensial dengan densitas $f\left(y_{i j}\right), Y_{i j}$ independen satu sama lain dengan diberikannya $b_{i}$ dengan $b_{i}$ adalah independen dan berdistribusi identik gaussian dengan mean nol dan $\operatorname{Var}\left(b_{i}\right)=\sigma_{b}^{2}=D$.

Misalkan $g\left(\mu_{i j}\right)=X_{i j}^{T} \beta+Z_{i j}^{T} b_{i}$ adalah fungsi penghubung dalam GLMM, fungsi likelihood untuk mengestimasi parameter $\beta$ adalah:

$$
L(\beta) \propto \prod_{i=1}^{m} \prod_{j=1}^{n_{i}} f\left(y_{i j}\right)
$$

$$
=\prod_{i=1}^{m} \prod_{j=1}^{n_{i}} \exp \left(\frac{y_{i j} \theta_{i j}-\psi\left(\theta_{i j}\right)}{\phi}+c\left(y_{i j}, \phi\right)\right)
$$

Kemudian fungsi log likelihood-nya adalah:

$$
l(\beta)=\sum_{i=1}^{m} \sum_{j=1}^{n_{i}} \frac{y_{i j} \theta_{i j}-\psi\left(\theta_{i}\right)}{\phi}+\sum_{i=1}^{m} \sum_{j=1}^{n_{i}} c\left(y_{i j}, \phi\right)
$$

Turunan pertama fungsi log likelihoodl $(\beta)$ adalah:

$$
\frac{\partial l(\beta)}{\partial \beta}=\sum_{i=1}^{m} \sum_{j=1}^{n_{i}}\left(y_{i j}-\mu_{i j}\right) \Delta^{-1}\left(Z_{i j} D Z_{i j}^{T}+R\right)^{-1} X_{i j}^{T}
$$

dengan $\Delta=g_{\mu}\left(\mu_{i}\right)$.

Persamaan (14) dapat dinotasikan menggunakan matriks, yaitu: 


$$
\frac{\partial l(\beta)}{\partial \beta}=X^{T}\left(Z D Z^{T}+R\right)^{-1} \Delta^{-1}(Y-\mu)
$$

Estimasi maksimum likelihood dari $\beta$ diperoleh dengan menentukan pembuat nol dari derivatif parsial turunan pertama fungsi $\log \operatorname{likelihood} l(\beta)$ terhadap $\beta$, yaitu:

$$
X^{T}\left(Z D Z^{T}+R\right)^{-1} \Delta^{-1}(Y-\mu)=0
$$

Persamaan (16) merupakan fungsi non linear jadi tidak dapat diselesaikan secara analitik, sehingga dapat digunakan suatu metode numerik misalnya Newton-Raphson. Turunan kedua fungsi log likelihoodl $(\beta)$ adalah:

$$
\frac{\partial^{2} l(\beta)}{\partial \beta \partial \beta^{T}}=-X^{T}\left(Z D Z^{T}+R\right)^{-1} \Delta^{-1} \frac{\partial \mu}{\partial \beta^{T}}+X^{T} \frac{\partial\left(Z D Z^{T}+R\right)^{-1} \Delta^{-1}}{\partial \beta^{T}}(Y-\mu)
$$

Scoring Algorithm dengan iterasi ke- $m+1$ yaitu $\hat{\beta}^{(m+1)}$, secara iteratif menggunakan formula sebagai berikut:

$$
\hat{\beta}^{(m+1)}=\hat{\beta}^{(m)}+\left(X^{T}\left(Z D Z^{T}+R\right)^{-1} X\right)^{-1} X^{T}\left(Z D Z^{T}+R\right)^{-1} \Delta^{-1}(Y-\mu)
$$

Jika $\hat{\beta}^{(m+1)} \approx \hat{\beta}^{(m)}$ (misalkan $\left\|\hat{\beta}^{(m+1)}-\hat{\beta}^{(m)}\right\|<\varepsilon$, dengan $\varepsilon$ adalah suatu bilangan positif yang sangat kecil sekali dan mendekati nol) maka proses iterasi berhenti dan kemudian diambil $\hat{\beta}^{(m+1)}$ sebagai estimasi dari $\beta$.

Nilai efek random $b_{i}$ pada GLMM tidak dapat diestimasi namun dapat diprediksi karena $b_{i}$ bukan parameter.Untuk mencari prediksi $b_{i}$ digunakan ekspektasi bersyarat dari efek random $b_{i}$, diberikan variabel dependen $Y_{i j}$ yaitu:

$$
\hat{b}_{i}=E\left(b_{i}\right)+\operatorname{cov}\left(b_{i}, Y_{i j}\right)\left(\operatorname{cov}\left(Y_{i j}\right)\right)^{-1}\left(Y_{i j}-E\left(Y_{i j}\right)\right)
$$

Kovarian $b_{i}$ dengan $Y_{i j}$ adalah:

$$
\operatorname{cov}\left(b_{i}, Y_{i j}\right)=\operatorname{cov}\left(b_{i}, X_{i j} \beta+Z_{i j} b_{i}+\varepsilon_{i j}\right)=D Z_{i j}^{T}
$$

Sehingga

$$
\hat{b}_{i}=D Z_{i j}^{T}\left(Z_{i j} D Z_{i j}^{T}+R\right)^{-1}\left(Y_{i j}-X_{i j} \beta\right)
$$


Model mortalita $\left(q_{i t}\right)$ adalah probabilitas seorang $i$ meninggal pada usia $t$. Karena dalam GLMM responnya biner dan berdistribusi binomial maka fungsi logit digunakan sebagai link function untuk menghubungkan $q_{i t}$ ke prediktor linear $\left(X_{i t} \beta+Z_{i t} b_{i}\right)$ .(Rohmaniah, 2015)Didefinisikan $E\left(Y_{i t} \mid X_{i t}\right)$ ekuivalen dengan kondisi probabilitas individu $i$ meninggal dalam usia $t$ dimana individu hidup pada awal periode dengan karakteristik $X_{i t}$, seperti:

$$
q_{i t}=\operatorname{Pr}\left[T_{i}=t \mid T_{i} \geq t, X_{i t}\right]
$$

Dimana $T_{i}$ adalah variabel random diskrit dengan waktu kematian individu $i$ tidak tersensor, dan $X_{i t}$ adalah vektor observasi kovariat (faktor underwriting) untuk individu $i$ pada usia $t$. Dengan menggunakan fungsi penghubung logit, maka diperoleh model:

$$
q_{i t}=\frac{\exp \left(X_{i t} \beta+Z_{i t} b_{i}\right)}{\left(1+\exp \left(X_{i t} \beta+Z_{i t} b_{i}\right)\right)}
$$

Dalam kerangka GLMM, representasi yang sesuai untuk memodelkan frailty adalah $b_{i}$, sehingga model mortalita tahunan untuk GLMM adalah:

$$
q_{i t}=\frac{\exp \left(X_{i t} \beta+b_{i}\right)}{\left(1+\exp \left(X_{i t} \beta+b_{i}\right)\right)}
$$

Sedangkan model mortalita dua tahunan adalah:

$$
{ }_{2} q_{i t}=\frac{\exp \left(X_{i t} \hat{\beta}+\hat{b}_{i}\right)}{\left(1+\exp \left(X_{i t} \hat{\beta}+\hat{b}_{i}\right)\right)}
$$

\section{HASIL DAN PEMBAHASAN}

A. Data Health and Retirement Study (HRS)

Health and Retirement Study (HRS) merupakan studi longitudinal yang mensurvei penduduk Amerika yang berusia diatas 50 tahun. Survei dilakukan setiap dua tahun sekali. Penelitian ini menggunakan data 106 penduduk berjenis kelamin laki-laki dan berusia 51-74 tahun selama 12tahun. Data tersebut mengenai usia, status merokok, status peminum alkohol, dan riwayat kesehatan meliputikolesterol, jantung, stroke dan diabetes yang merupakan faktor-faktor underwriting dan digunakan sebagai variabel independen $(\mathrm{X})$, sedangkan sebagai variabel dependen $(\mathrm{Y})$ adalah kematian. 
B. Ilustrasi Model

Ilustrasi model mortalita dengan pengaruh frailty dilakukan dengan menggunakan Generalized Linear Mixed Models (GLMM). Sedangkan ilustrasi model mortalita tanpa pengaruh frailtydilakukan dengan menggunakan Generalized Linear Models (GLM). Karena data yang digunakan adalah data dua tahunan, maka model mortalita yang diperoleh merupakan estimasi probabilitas kematian dalam selang dua tahun, dan dinotasikan dengan ${ }_{2} q_{i t}$ yaitu probabilitas seorang $i$ meninggal pada usia $t$ untuk dua tahun kedepan.

\section{Model 1 (dengan faktorunderwriting tanpa frailty)}

$$
\begin{aligned}
& { }_{2} q_{i t}=\frac{\exp \left(X_{i t} \hat{\beta}\right)}{1+\exp \left(X_{i t} \hat{\beta}\right)} \\
& \Leftrightarrow{ }_{2} q_{i t}=\frac{\exp \left(\hat{\beta}_{0}+\hat{\beta}_{1} U S A_{i t}+\hat{\beta}_{2} R K K_{i t}+\hat{\beta}_{3} A L K_{i t}+\hat{\beta}_{4} K S T_{i t}+\hat{\beta}_{\mathrm{9}} J T G_{i t}+\hat{\beta}_{6} S T R_{i t}+\hat{\beta}_{\mathrm{7}} D B T_{i t}\right)}{1+\exp \left(\hat{\beta}_{0}+\hat{\beta}_{1} U S A_{i t}+\hat{\beta}_{2} R K K_{i t}+\hat{\beta}_{3} A L K_{i t}+\hat{\beta}_{4} K S T_{i t}+\hat{\beta}_{\mathrm{g}} J T G_{i t}+\hat{\beta}_{6} S T R_{i t}+\hat{\beta}_{\mathrm{t}} D B T_{i t}\right)}
\end{aligned}
$$

\section{Model 2 (dengan faktorunderwriting dan frailty)}

$$
\begin{aligned}
& { }_{2} q_{i t}=\frac{\exp \left(X_{i t} \hat{\beta}+\hat{b}_{i}\right)}{1+\exp \left(X_{i t} \hat{\beta}+\hat{b}_{i}\right)} \\
& \Leftrightarrow{ }_{2} q_{i t}=\frac{\exp \left(\hat{\beta}_{0}+\hat{\beta}_{1} U S A_{i t}+\hat{\beta}_{2} R K K_{i t}+\hat{\beta}_{3} A L K_{i t}+\hat{\beta}_{4} K S T_{i t}+\hat{\beta}_{\mathrm{g}} J T G_{i t}+\hat{\beta}_{6} S T R_{i t}+\hat{\beta}_{\mathrm{7}} D B T_{i t}+\hat{b}_{i}\right)}{1+\exp \left(\hat{\beta}_{0}+\hat{\beta}_{1} U S A_{i t}+\hat{\beta}_{2} R K K_{i t}+\hat{\beta}_{3} A L K_{i t}+\hat{\beta}_{4} K S T_{i t}+\hat{\beta}_{\mathrm{g}} J T G_{i t}+\hat{\beta}_{6} S T R_{i t}+\hat{\beta}_{\mathrm{7}} D B T_{i t}+\hat{b}_{i}\right)}
\end{aligned}
$$

C. Estimasi Parameter Model Tanpa Pengaruh Frailty (Model 1)

Estimasi parameter dilakukan menggunakan software $R$ dimana perintah glm pada librarystats digunakan untuk model tanpa pengaruh frailty. 


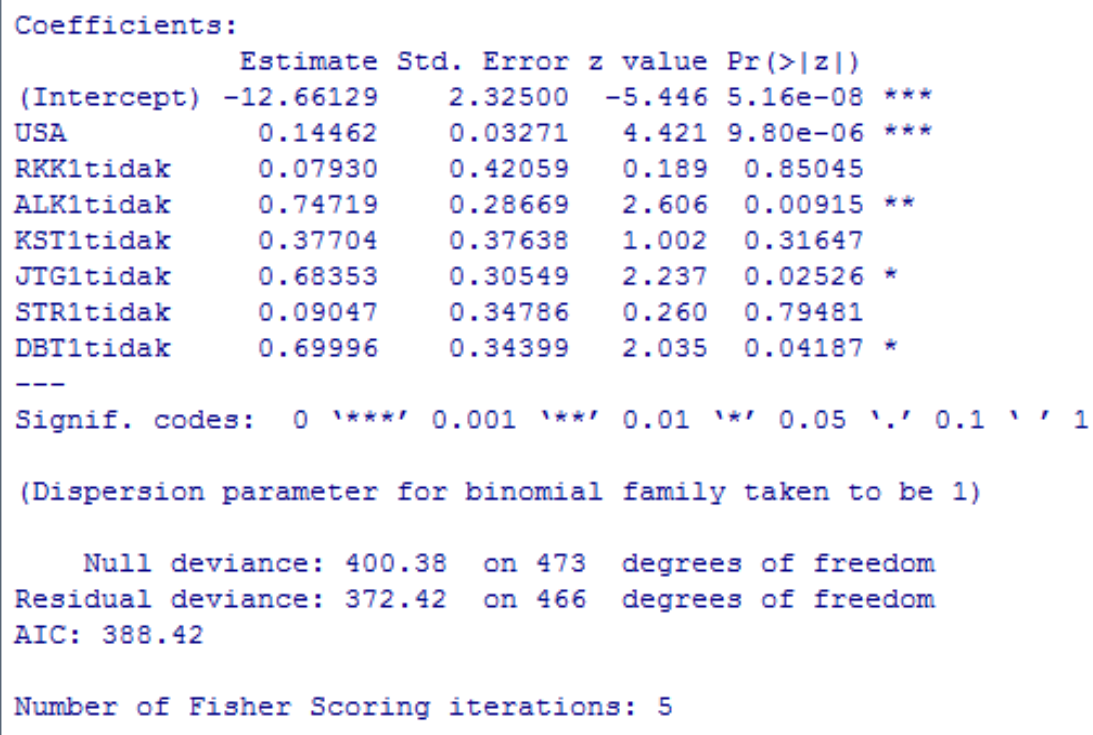

Gambar 1. Hasil Estimasi Parameter Model 1

Pemilihan variabel independen terbaik yang secara statistik mempengaruhi variabel dependen dilakukan dengan metode eliminasi mundur (backward). Tingkat signifikansi $\alpha=0.05$ dan daerah kritis $H_{0}$ ditolak jika $p$-value $<\alpha$. Berdasarkan Gambar 1 diperoleh RKK (status individu sebagai perokok) mempunyai nilai $p$-value terbesar yaitu 0.85045 dan lebih dari $\alpha$. Artinya RKK tidak berpengaruh terhadap model, sehingga variabel tersebut dihapus. Langkah dilanjutkan sampai diperoleh model dengan variabel independen terbaik.

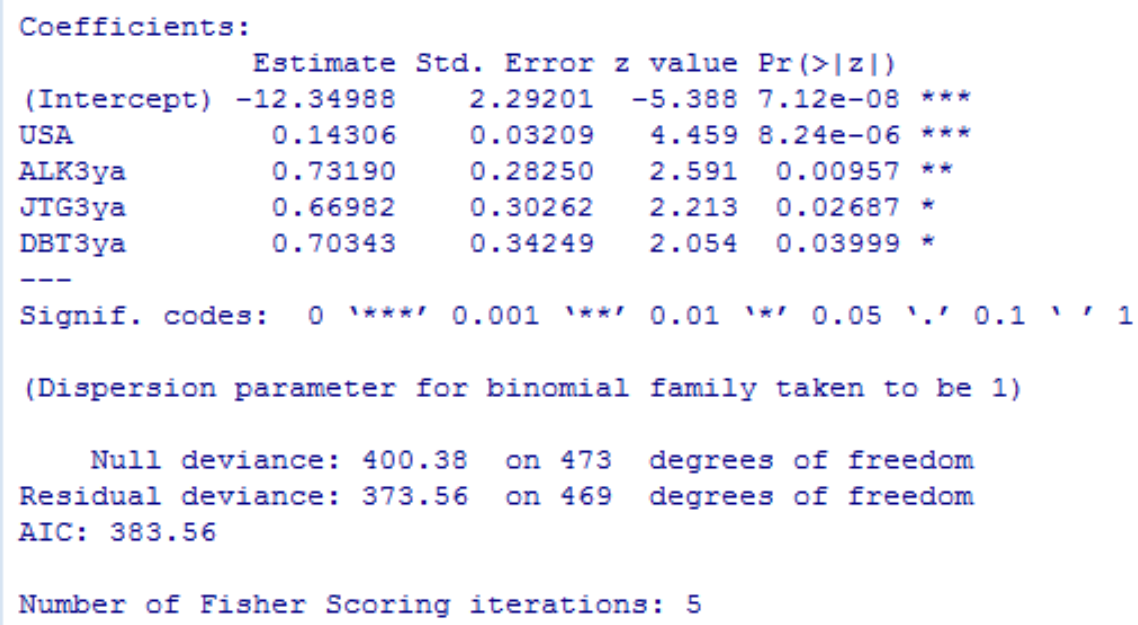

Gambar 2. Hasil Estimasi Parameter Model 1 Dengan Variabel Independen Terbaik

Berdasarkan Gambar 2 diperoleh semua nilai p-value kurang dari kriteria $\alpha$, sehingga variabel prediktor tersebut merupakan variabel independen terbaik dan merupakan model terbaik untuk model mortalita dengan faktorunderwriting tanpa frailty. 
D. Estimasi Parameter Model dengan Pengaruh Frailty (Model 2)

Estimasi parameter dan prediksi nilai frailty untuk model dengan pengaruh frailty dilakukan menggunakan software $R$ dengan perintah glmer pada library lme4.

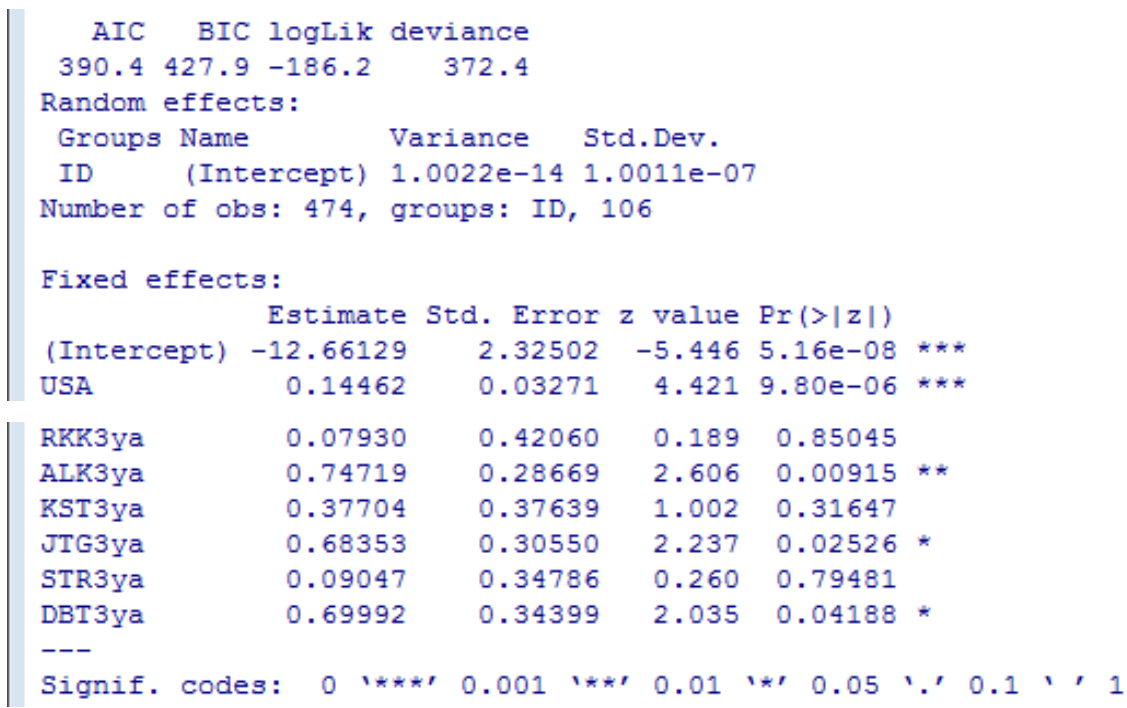

Gambar 3. Hasil Estimasi Parameter Model 2

Berdasarkan Gambar 3 diperoleh RKK (status individu sebagai perokok) mempunyai nilai $p$-value terbesar yaitu 0.85045 dan lebih dari $\alpha$. Artinya RKK tidak berpengaruh terhadap model, sehingga variabel tersebut dihapus. Besarnya AIC untuk model tersebut adalah 390.4. Langkah dilanjutkan sampai diperoleh model dengan variabel independen terbaik.

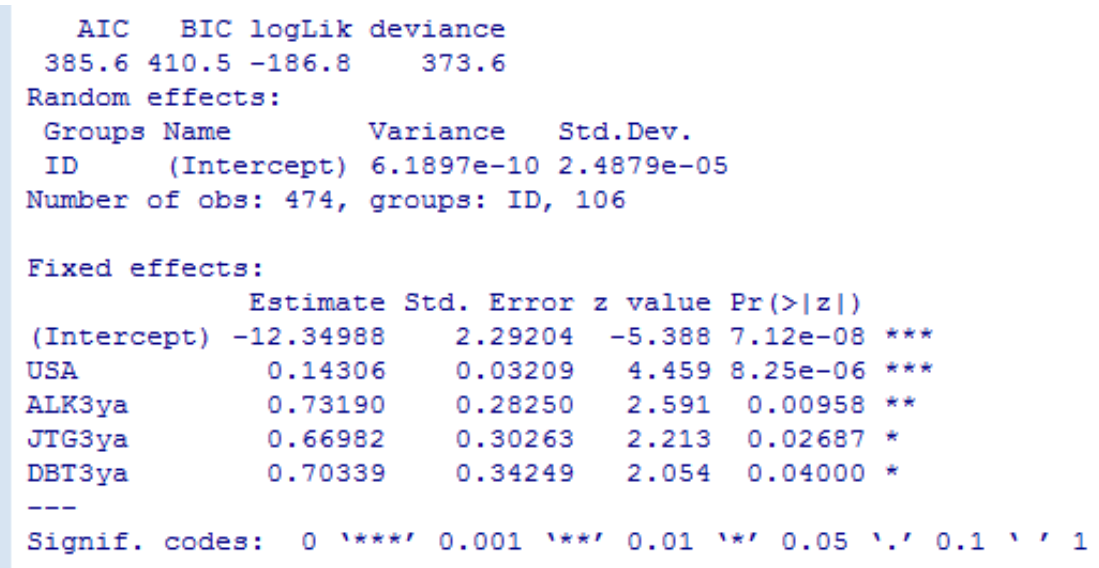

\section{Gambar 4. Hasil Estimasi Parameter Model 2 DenganVariabel Independen} Terbaik

Berdasarkan Gambar 4 diperoleh semua nilai $p$-value kurang dari kriteria $\alpha$, sehingga variabel prediktor tersebut merupakan variabel independen terbaik. Model di atas mempunyai nilai AIC paling minimal dibandingkan dengan model-model 
sebelumnya yaitu sebesar 385.6, sehingga model tersebut merupakan model terbaik untuk model mortalita dengan faktorunderwriting dan frailty.

Efek random (frailty) dapat diperoleh menggunakan perintah ranef pada library lme4.

Tabel 1. Nilai Frailty

\begin{tabular}{rccccc}
\hline id & frailty & id & frailty & id & frailty \\
\hline $\mathbf{1}$ & $-2.991058 \mathrm{e}-10$ & $\mathbf{6}$ & $3.758272 \mathrm{e}-10$ & $\mathbf{1 1}$ & $-2.983433 \mathrm{e}-10$ \\
$\mathbf{2}$ & $-1.718750 \mathrm{e}-10$ & $\mathbf{7}$ & $4.674630 \mathrm{e}-10$ & $\mathbf{1 2}$ & $-3.639254 \mathrm{e}-10$ \\
$\mathbf{3}$ & $5.571770 \mathrm{e}-10$ & $\mathbf{8}$ & $-3.458163 \mathrm{e}-10$ & $\mathbf{1 3}$ & $5.129357 \mathrm{e}-10$ \\
$\mathbf{4}$ & $-1.966275 \mathrm{e}-10$ & $\mathbf{9}$ & $-3.767270 \mathrm{e}-10$ & $\mathbf{1 4}$ & $5.655495 \mathrm{e}-10$ \\
$\mathbf{5}$ & $-2.996147 \mathrm{e}-10$ & $\mathbf{1 0}$ & $-2.619193 \mathrm{e}-10$ & $\mathbf{1 5}$ & $-2.130916 \mathrm{e}-10$ \\
\hline
\end{tabular}

E. Model Mortalita

Berdasarkan estimasi parameter, diperoleh model mortalita sebagai berikut:

\section{Model 1}

${ }_{2} q_{i t}=\frac{\exp \left(-12.34988+0.14306 U S A_{i t}+0.7319 A L K_{i t}+0.66982 J T G_{i t}+0.70343 D B T_{i t}\right)}{1+\exp \left(-12.34988+0.14306 U S A_{i t}+0.7319 A L K_{i t}+0.66982 J T G_{i t}+0.70343 D B T_{i t}\right)}$

\section{Model 2}

$$
{ }_{2} q_{i t}=\frac{\exp \left(-12.34988+0.14306 U S A_{i t}+0.7319 A L K_{i t}+0.66982 J T G_{i t}+0.70339 D B T_{i t}+\hat{b}_{i}\right)}{1+\exp \left(-12.34988+0.14306 U S A_{i t}+0.7319 A L K_{i t}+0.66982 J T G_{i t}+0.70339 D B T_{i t}+\hat{b}_{i}\right)}
$$

Sebagai contoh untuk individu $i=4$ pada usia 57 menderita jantung dan diabetes, mempunyai resiko kematian sebagai berikut:

Model 1

${ }_{2} q_{i=4 t=57}=\frac{\exp (-12.34988+0.14306(57)+0.66982+0.70343)}{1+\exp (-12.34988+0.14306(57)+0.66982+0.70343)}=0.0561357229$

Model 2 dengan frailty untuk individu $i=4$ sebesar $-1.966275 \mathrm{e}-10$

${ }_{2} q_{i=4 t=57}=\frac{\exp (-12.34988+0.14306(57)+0.66982+0.70339+(-1.966275 \mathrm{e}-10))}{1+\exp (-12.34988+0.14306(57)+0.66982+0.70339+(-1.966275 \mathrm{e}-10))}=0.0561253056$

Jadi frailty berpengaruh dalam pemodelan mortalita, frailty yang bernilai negatif menunjukkan tingkat kerentanan seseorang kecil, sebaliknya frailty yang bernilai 
positif menunjukkan tingkat kerentanan seseorang dalam mengalami rsiko kematian lebih besar.

\section{SIMPULAN DAN SARAN}

Berdasarkan analisis menggunakan model 1 dan model 2 diperoleh bahwa frailty sangat berpengaruh dalam pemodelan mortalita. Frailty yang bernilai positif menunjukkan bahwa tingkat kerentanan seseorang dalam mengalami risiko kematian lebih besar daripada frailty yang bernilai negatif. Sehingga model mortalita dengan faktor underwriting dan frailty dapat diaplikasikan untuk menghitung besarnya premi asuransi jiwa.

Dalam penelitian ini probabilitas kematian yang diperoleh adalah untuk dua tahun kedepan, untuk penelitian selanjutnya diharapkan dapat menggunakan data tahunan dari Indonesia sehingga probabilitas kematian yang diperoleh adalah untuk satu tahun kedepan dan frailty dapat diaplikasikan selain pada asuransi jiwa, diantaranya asuransi kerugian atau asuransi umum.

\section{DAFTAR PUSTAKA}

Brown, R. L., \& McDaid, J. (2003). Factors affecting retirement mortality. North American Actuarial Journal, 7(2), 24-43.

Gałecki, A., \& Burzykowski, T. (2013). Linear mixed-effects models using R: A step-bystep approach. Springer Science \& Business Media.

McCullagh, P., \& Nelder, J. A. (1989). Generalized linear models (Vol. 37). CRC press.

Rohmaniah, S. A. (2015). PEMODELAN MORTALITA DENGAN FAKTOR UNDERWRITING DAN FRAILTY MENGGUNAKAN GENERALIZED LINEAR MIXED MODELS DAN APLIKASINYA DALAM MENENTUKAN HARGA PREMI. Yogyakarta: [Yogyakarta]: Universitas Gadjah Mada. Retrieved from

http://etd.repository.ugm.ac.id/index.php?mod=penelitian_detail\&sub=Penelitian Detail\&act=view\&typ=html\&buku_id=77326

Rohmaniah, S. A., \& Danardono. (2017). Perhitungan harga premi model dua tahunan dengan faktor underwriting menggunakan generalized linear models. Jurnal Ilmiah UMS, l(Knpmp Ii), 124-132. Retrieved from https://publikasiilmiah.ums.ac.id/bitstream/handle/11617/8745/M-12 Siti Alfiatur Rohmaniah dan Danardono hal 124-132.pdf?sequence=1\&isAllowed=y

Vaupel, J. W., Manton, K. G., \& Stallard, E. (1979). The impact of heterogeneity in individual frailty on the dynamics of mortality. Demography, 16(3), 439-454. 